\title{
Operative Treatment of Isolated Bicondylar Hoffa Fracture With a Modified Swashbuckler Approach
}

\author{
Ramanath K. Sharath, ${ }^{1, *}$ Daksh Gadi, ${ }^{1}$ Amit Grover, ${ }^{1}$ and Sandeep Kumar Gour ${ }^{1}$ \\ ${ }^{1}$ Department of Orthopaedics, MS Ramaiah Medical College, Bangalore, India \\ ${ }^{*}$ Corresponding author: Ramanath K. Sharath, Department of Orthopaedics, MS Ramaiah Medical College, Bangalore, India. Tel:+91-9945815821, E-mail: dr.sharathkr@gmail.com \\ Received 2014 November 26; Accepted 2015 February 19.
}

\begin{abstract}
Introduction: An isolated coronal fracture of either or both femoral condyles is a rare entity and is usually associated with high-energy injury trauma. Such fractures should be meticulously fixed for a good functional outcome as they involve the articular surface of a weight bearing joint. A modified swashbuckler approach provides adequate exposure for appropriate reduction and fixation of such fractures. Case Presentation: A 32-year-old male sustained a bicondylar Hoffa fracture of the right femur which was treated by open reduction and internal fixation using a modified swashbuckler approach. At two years of follow-up, the patient had excellent radiological and functional outcome.

Conclusions: In our study, we treated this rare fracture successfully using a modified swashbuckler approach and found it to be a good approach for such fractures as compared to the conventional approach.

Keywords: Bicondylar, Hoffa Fracture, Swashbuckler Approach
\end{abstract}

\section{Introduction}

Coronal fracture of distal femur is a rare entity and more so if it is a bicondylar Hoffa fracture (1). Friedrich Busch had first described this fracture (2), but later all coronal split fractures were named after Albert Hoffa (3). The Hoffa fractures more commonly are lateral condylar split fractures because the usual mechanism of injury is axial transmission of ground reaction force directed posteriorly in a flexed knee joint. Rarely, due to direct impact over the knee may direct such force transmission to both condyles leading to a bicondylar Hoffa. Such intra articular fractures are unstable and require operative fixation.

Coronal plane fractures of the distal part of the femur are markers of high-energy injury mechanisms. Hoffa fractures are commonly missed on usual anteroposterior and lateral views of plain radiographs therefore can be better appreciated on different cuts of computed tomography (CT) scans (4).

\section{Case Presentation}

A thirty-two year old man with a history of high energy trauma sustained a closed injury to his right knee. Patient complained of severe pain in the right knee and was unable to bear weight/walk. On physical examination, swelling was noted and tenderness was elicited with restricted range of movement in the right knee. No distal neurovascular deficits were present and patient was eval- uated using plain radiographs. Radiographic evaluation revealed bicondylar Hoffa fracture of right distal femur (Figure 1). Since the fracture was involving both condyles, a conventional approach would not suffice and thus fracture fixation using Swashbuckler approach (Figure 2) was planned. The Swashbuckler approach is a lateral approach extended distally between lateral patellar retinaculum and the vastus lateralis muscle to a lateral parapatellar arthotomy. The quadriceps muscle and patella are reflected medially to expose distal femur condyles.

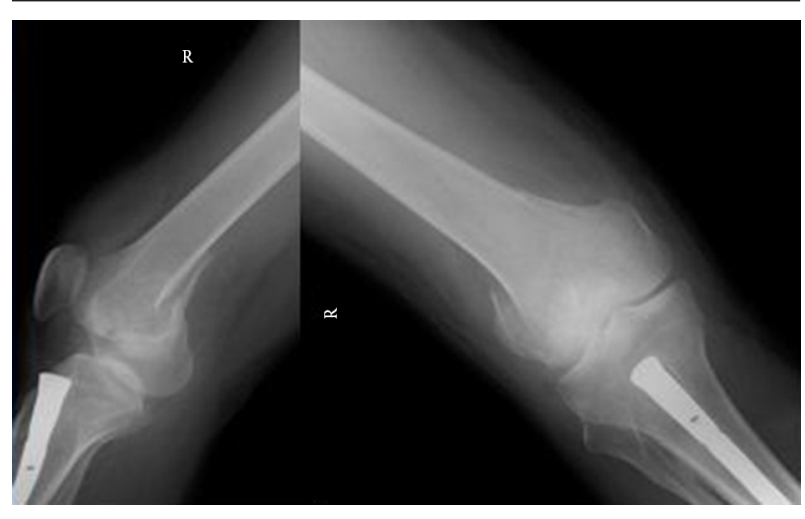

Figure 1. Preoperative Radiograph Showing Right Femur Hoffa Fracture

Copyright (C) 2015, Kashan University of Medical Sciences. This is an open-access article distributed under the terms of the Creative Commons Attribution-NonCommercial 4.0 International License (http://creativecommons.org/licenses/by-nc/4.0/) which permits copy and redistribute the material just in noncommercial usages, provided the original work is properly cited. 


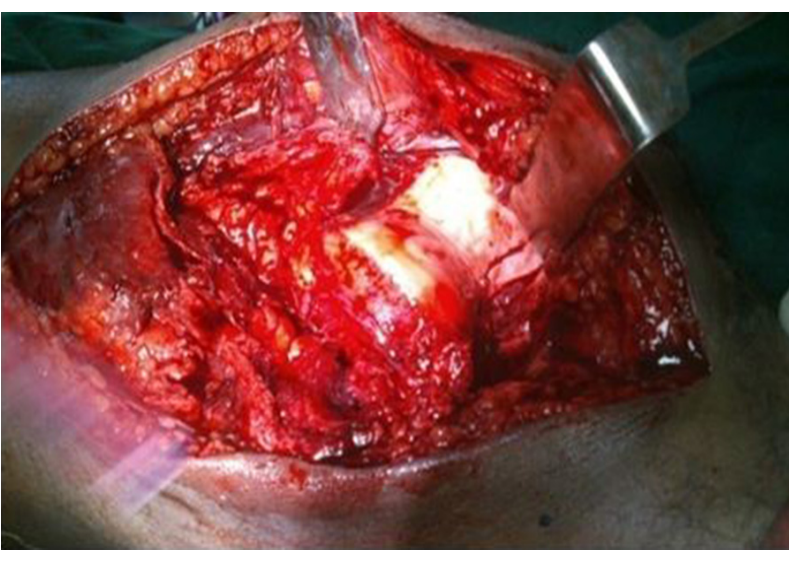

Figure 2. Intraoperative Picture Showing the Hoffa Fracture and the Swashbuckler Approach

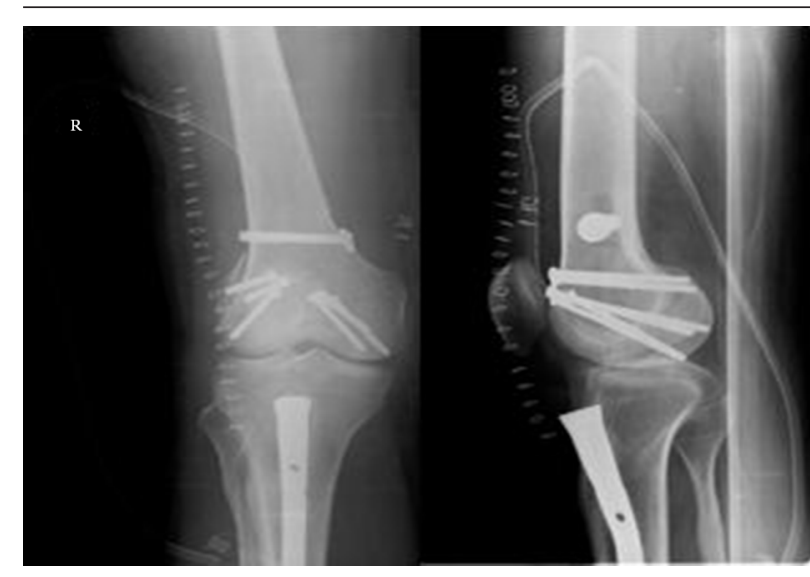

Figure 3. Postoperative Radiographs After Fixation
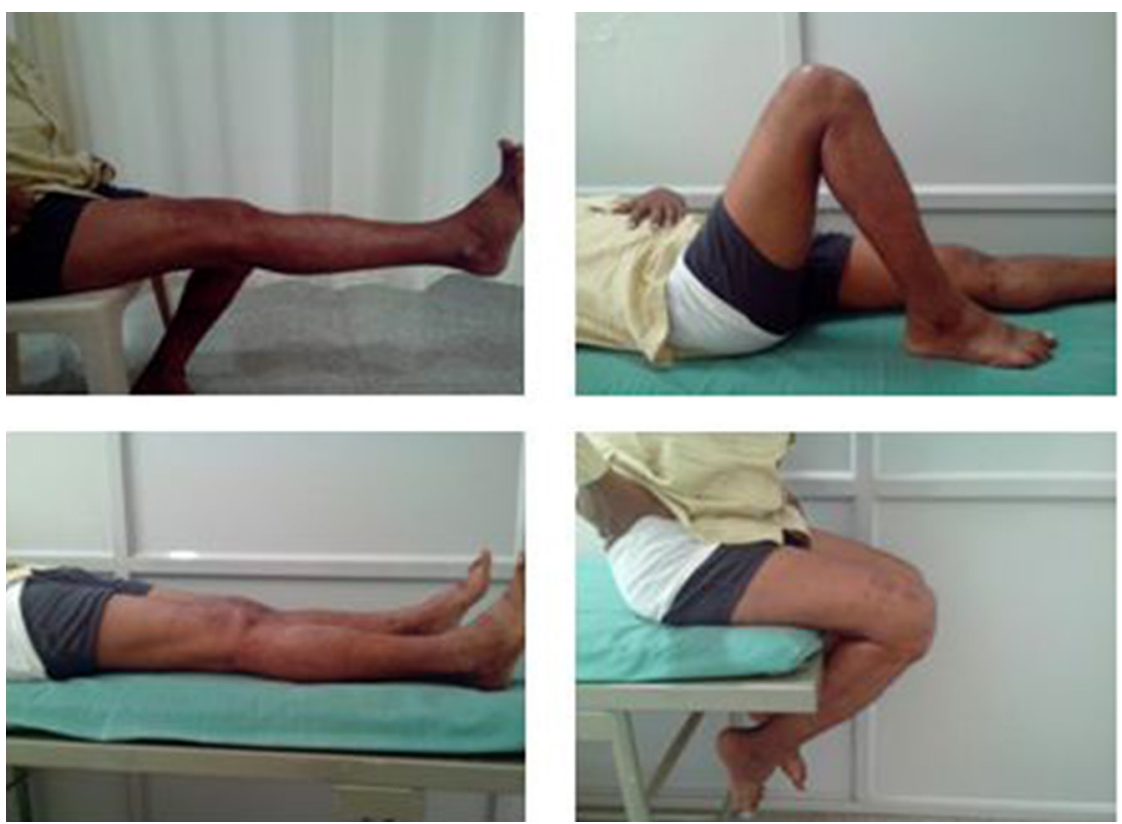

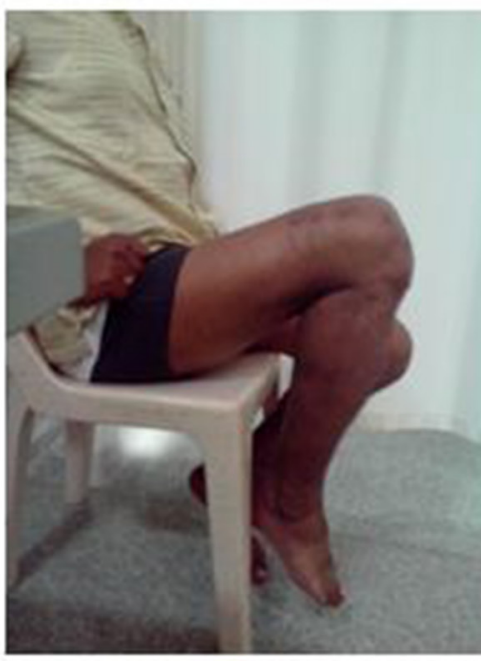

Figure 4. Functional Outcome After Two Years

Internal fixation was performed using three cancellous screws for each condyle directed anteroposteriorly. It was ensured that the entry of screws was proximal to the articular surface. Good fracture reduction was achieved. A transverse cancellous screw was also applied for proximal extent of the fracture line (Figure 3 ).

Postoperatively, the patient was advised absolute nonweight bearing walking with walker for 3 months. Active range-of-motion exercises were started from the second postoperative day.

At the end of two years follow-up, patient had a good functional outcome including sitting cross legged and squat (Figure 4). On physical examination painless range of movement of 0 to 120 degree at the knee was noted.

Fracture union was confirmed by plain radiographs at
2 years of follow-up. The above- functional results were considered excellent using HSS scores.

\section{Discussion}

Physiological genu valgum makes lateral condyle very vulnerable to coronal split in a high energy trauma. Such high energy traumas are more common in adults and people associated with high-velocity sporting activities, thus explaining the mechanism of injury in a flexed and abducted knee.

Such bicondylar Hoffa fractures need to be evaluated by CT Scans because of erroneous interpretation of plain radiographs that is missing a fracture in anteroposterior view due to the intact anterior part of the condyle (5) or 
misinterpreting a bicondylar fracture as a unicondylar one in a lateral view.

Being an unstable fracture involving a weight bearing joint, achieving good functional outcome mandates adequate reduction of the fracture which can only be achieved by a operative technique with a good exposure (6-8).

The distal end of femur has minimal soft tissue attachment in the posterior aspect; so, if such fractures are not adequately fixed, it may lead to complications like nonunion and avascular necrosis $(9,10)$. Operative treatment provides early functional rehabilitation and also decreases the chances of osteoarthritis. Previous studies have shown good results using parapatellar approach for such fracture fixation (11). These are usually associated with other injuries like extensor mechanism rupture (12), patellar fracture, tibial spine avulsion $(13,14)$ femoral shaft fracture etc. Prompt diagnosis and treatment with multiple cancellous screws using modified lateral parapatellar approach is ideal. The goal of the treatment is to achieve anatomical reduction of the joint surface with stable internal fixation so that early mobilization can be done.

For good exposure and reduction, a medial parapatellar approach is recommended whereas favorable outcomes have been achieved with anterior and lateral approaches (15).

To conclude, the bicondylar Hoffa fracture is a rare fracture and being an intraarticular fracture, it needs to be fixed meticulously. Thus, the modified swashbuckler approach provides adequate exposure for appropriate reduction and fixation of such fractures. This approach helps in minimizing complications by reducing the operative time for reduction in such complex fractures.

\section{Footnote}

Authors' Contribution:Study concept and design: Ramanath K. Sharath; acquisition of data: Daksh Gadi; analysis and interpretation of data: Amit Grover; drafting of the manuscript: Sandeep Kumar Gour.

\section{References}

1. Dua A, Shamshery PK. Bicondylar Hoffa fracture: open reduction internal fixation using the swashbuckler approach. J Knee Surg. 2010;23(1):21-4. [PubMed: 20812577]

2. Heuschen UA, Gohring U, Meeder PJ. [Bilateral Hoffa fracture--a rarity]. Aktuelle Traumatol.1994;24(3):83-6. [PubMed: 8048369]

3. Hoffa A. Textbook of fractures and dislocations of doctors and students [German]. F. Enke; 1896.

4. Nork SE, Segina DN, Aflatoon K, Barei DP, Henley MB, Holt S, et al. The association between supracondylar-intercondylar distal femoral fractures and coronal plane fractures. $J$ Bone Joint Surg Am. 2005;87(3):564-9. doi: 10.2106/JBJS.D.01751. [PubMed: 15741623]

5. Allmann KH, Altehoefer C, Wildanger G, Gufler H, Uhl M, Seif el Nasr M, et al. Hoffa fracture--a radiologic diagnostic approach. J Belge Radiol.1996;79(5):201-2. [PubMed: 8958668]

6. Letenneur J, Labour PE, Rogez JM, Lignon J, Bainvel JV. [Hoffa's fractures. Report of 20 cases (author's transl)]. Ann Chir.1978;32(34):213-9. [PubMed: 697301]

7. Kumar R, Malhotra R. The Hoffa fracture: three case reports. J Orthop Surg. 2001;9(2)

8. Ostermann PA, Neumann K, Ekkernkamp A, Muhr G. Long term results of unicondylar fractures of the femur. J Orthop Trauma. 1994;8(2):142-6. [PubMed: 8207571]

9. Zeebregts CJ, Zimmerman KW, ten Duis HJ. Operative treatment of a unilateral bicondylar fracture of the femur. Acta Chir Belg. 2000;100(3):104-6. [PubMed:11280171]

10. Papadopoulos AX, Panagopoulos A, Karageorgos A, Tyllianakis M. Operative Treatment of Unilateral Bicondylar Hoffa Fractures. J Orthop Trauma. 2004;18(2):119-22. doi: 10.1097/00005131200402000-00012. [PubMed: 14743034]

11. Holmes SM, Bomback D, Baumgaertner MR. Coronal fractures of the femoral condyle: a brief report of five cases. J Orthop Trauma. 2004;18(5):316-9. [PubMed: 15105756]

12. Calmet J, Mellado JM, Garcia Forcada IL, Gine J. Open bicondylar Hoffa fracture associated with extensor mechanism injury. J Orthop Trauma. 2004;18(5):323-5. [PubMed: 15105758]

13. Barei DP, Schildhauer TA, Nork SE. Noncontiguous fractures of the femoral neck, femoral shaft, and distal femur. J Trauma. 2003;55(1):80-6. doi: 10.1097/01.TA.0000046259.43886.25. [PubMed: 12855885]

14. Miyamoto R, Fornari E, Tejwani NC. Hoffa fragment associated with a femoral shaft fracture. A case report. I Bone Joint Surg Am. 2006;88(10):2270-4. doi: 10.2106/JBJS.E.01003. [PubMed: 17015607]

15. Helfet DL. Fractures of the distal femur. In: Browner B. D., Jupiter J. B., Levine A. M., Trafton P. G., editors. Skeletal trauma. Philadelphia: Saunders; 1992. pp. 1643-83. 